\title{
KAJIAN KINERJA SIMPANG BERSINYAL BUNDARAN KECIL DAN SIMPANG TAMBUN BUNGAI DI PALANGKA RAYA KALIMANTAN TENGAH
}

\author{
Ari Widya Permana ${ }^{1}$, M. Zainul Arifin ${ }^{2}$, Hendi Bowoputro ${ }^{3}$ \\ ${ }^{1}$ Mahasiswa / Program Magister / Teknik Sipil / Fakultas Teknik / Universitas Brawijaya \\ Malang \\ ${ }^{2,3}$ Dosen / Teknik Sipil / Fakultas Teknik / Universitas Brawijaya Malang \\ Jl. MT Haryono 167, Malang 65145, Indonesia
}

Korespondensi : ari.w.permana@gmail.com

\begin{abstract}
Bundaran Kecil intersection is close to Tambun Bungai intersection, so vehicle must stop at each intersection because it gets red signal. To reduce delay and queue, signal coordination is required. Primary data include vehicle volume, geometric intersection and roundabout, signal timing, saturation flow, and travel time. Method used are Indonesian highway capacity manual (IHCM) 1997 and saturation flow approach method. From analysis, on roundabout, degree of saturation at weaving DA (R. T. A. Milono street - G. Obos street) reached 0.901. On signalized intersection, average delay value is $>60 \mathrm{sec} / \mathrm{pcu}($ LOS F). Best scenario is 8 th scenario with cycle time of 90 seconds and has LOS D. Based on coordination diagram obtained offset of 40 seconds and bandwidth of 13 seconds.
\end{abstract}

Keywords: Bandwidth, offset, signal coordination, signalized roundabout.

\section{PENDAHULUAN}

Palangka Raya merupakan ibukota Provinsi Kalimantan Tengah yang pembangunannya saat ini terus mengalami peningkatan seiring dengan bertambahnya jumlah penduduk dan semakin pesatnya kegiatan sosial ekonomi masyarakat.

Menurut data dari Badan Pusat Statistik Kota Palangka Raya (2016), jumlah penduduk Kota Palangka Raya pada tahun 2015 berjumlah 259.865 orang, dengan tingkat pertumbuhan penduduk sebesar $3,08 \%$. Sejalan dengan itu, kebutuhan akan transportasi juga semakin meningkat.

Simpang Bundaran Kecil adalah simpang empat bersinyal dengan bundaran yang terletak sebagai titik pertemuan arus lalu lintas dari empat kaki simpang yang merupakan jalan arteri primer (Jln. RTA Milono dan Jln. Imam Bonjol) serta jalan kolektor primer (Jln. Diponegoro dan Jln G.Obos) di Kota Palangka Raya. Dimana dilalui arus lalu lintas antar daerah dan lokasinya strategis sebagai prasarana penunjang segala aktivitas di lingkungan sekitarnya yang merupakan area perkantoran, pendidikan, pertokoan, dan pemukiman. Salah satu simpang yang lokasinya berdekatan yaitu simpang Tambun Bungai yang berjarak \pm 220 meter dan dihubungkan oleh ruas jalan Diponegoro.

Pada simpang yang berdekatan terkadang timbul permasalahan yaitu lamanya tundaan serta antrian kendaraan yang cukup panjang sehingga mengakibatkan kurang nyamannya pengendara yang melewati simpang tersebut.

Salah satu usaha untuk mengurangi tundaan dan panjang antrian yang terjadi, yaitu dengan mengkoordinasi sinyal lampu lalu lintas pada kedua simpang tersebut. Dilakukan dengan mengutamakan jalan yang bervolume lebih besar.

Adapun tujuan dari kajian ini yaitu:

1. Mengetahui kinerja simpang bersinyal Bundaran Kecil pada kondisi eksisting dengan metode MKJI 1997 dan metode pendekatan arus jenuh.

2. Mengetahui kinerja bundaran pada simpang Bundaran Kecil.

3. Mendapatkan perancangan koordinasi sinyal pada simpang Bundaran kecil dan simpang 
Tambun Bungai untuk mengurangi tundaan

\section{TINJAUAN PUSTAKA}

Ada kalanya sebuah simpang bersinyal ditambah dengan bundaran untuk menambah kapasitasnya (Munawar, 2009) dimana harus dilakukan penyesuaian fase, yaitu berbeda dengan simpang bersinyal tanpa bundaran, fase dibuat berlawanan arah jarum jam.

Khisty \& Lall (2006) menyatakan bahwa kapasitas persimpangan dengan lampu lalu lintas didasarkan pada konsep arus jenuh dan lajur arus jenuh.

\subsection{Arus jenuh time slice}

Metode time slice adalah salah satu metode untuk melakukan pengukuran arus jenuh di simpang bersinyal yang dikembangkan oleh Road Research Laboratory, 1963 yang tercantum dalam "Road Note 34, A Method of Measuring Saturation Flow at Traffic Signal". Metode ini mengukur rata-rata kendaraan yang melewati garis henti ketika periode sinyal hijau dan membaginya berdasarkan potongan waktu (time slice) dengan interval yang lebih kecil (misalnya per enam detik) (Yuliantana \& Patandianan, 2013)

\subsection{Koordinasi sinyal}

\subsubsection{Syarat Koordinasi Sinyal}

Untuk mengkoordinasikan beberapa sinyal, diperlukan beberapa syarat yang harus dipenuhi (McShane \& Roess, 1990), yaitu:

1. Jarak antar simpang yang dikoordinasikan tidak lebih dari 800 meter. Jika lebih dari 800 meter maka kordinasi sinyal tidak akan efektif lagi.

2. Semua sinyal harus mempunyai panjang waktu siklus (cycle time) yang sama.

3. Umumnya digunakan pada jaringan jalan utama (arteri, kolektor) dan juga dapat digunakan untuk jaringan jalan yang berbentuk grid.

4. Terdapat sekelompok kendaraan (platoon) sebagai akibat lampu lalu lintas di bagian hulu.

\subsubsection{Offset dan Bandwidth}

Offset merupakan waktu antara permulaan fase sinyal hijau di satu simpang dengan permulaan sinyal hijau di simpang berikutnya (Khisty, 2006). Offset dipengaruhi oleh panjang ruas dan kecepatan kendaraan. dan antrian.

Bandwidth adalah perbedaan waktu dalam lintasan paralel sinyal hijau antara lintasan pertama dan lintasan terakhir.

\section{METODOLOGI PENELITIAN}

Lokasi kajian yaitu simpang Bundaran Kecil dan simpang Tambun Bungai di Kota Palangka Raya. Lokasi kajian seperti dalam Gambar 2.

Dalam bagan alir kajian seperti pada Gambar 1, data yang digunakan meliputi data primer dan sekunder. Data primer didapat dari hasil survei langsung, berupa volume kendaraan, geometrik simpang dan bundaran, waktu sinyal, arus jenuh eksisting time slice, dan waktu tempuh kendaraan.

Analisis kinerja bundaran menggunakan metode MKJI 1997. Analisis kinerja simpang bersinyal Bundaran Kecil menggunakan metode MKJI 1997 dan metode pendekatan arus jenuh. Sedangkan simpang bersinyal Tambun Bungai menggunakan metode MKJI 1997.

\subsection{Arus jenuh MKJI 1997}

Tahapan analisis arus jenuh dengan metode MKJI 1997 adalah sebagai berikut.

1. Menghitung arus jenuh dasar $\left(S_{0}\right)$, dipengaruhi oleh lebar efektif dan tipe pendekat (terlindung atau terlawan).

2. Menentukan faktor-faktor penyesuaian, yaitu faktor penyesuaian ukuran kota $\left(\mathrm{F}_{\mathrm{CS}}\right)$, faktor penyesuaian tipe lingkungan jalan $\left(\mathrm{F}_{\mathrm{SF}}\right)$, faktor penyesuaian kelandaian $\left(\mathrm{F}_{\mathrm{G}}\right)$, faktor penyesuaian parkir $\left(\mathrm{F}_{\mathrm{P}}\right)$, faktor penyesuaian belok kanan $\left(\mathrm{F}_{\mathrm{RT}}\right)$, faktor penyesuaian belok kiri $\left(\mathrm{F}_{\mathrm{LT}}\right)$.

3. Menghitung arus jenuh penyesuaian (S)

\subsection{Arus jenuh interval metode time slice}

Tahapan analisis arus jenuh dengan Metode Time Slice adalah sebagai berikut.

1. Mengklasifikasikan tipe kendaraan, yaitu kendaraan ringan (LV), kendaraan berat (HV), dan sepeda motor (MC).

2. Dari 30 data siklus sinyal yang diambil, dipilih data arus yang berada pada kondisi jenuh.

3. Mengonversi data arus ke dalam smp/jam dengan mengalikan arus kend/jam dengan emp (LV:1,0; HV:1,3; MC:0,2).

4. Merata-ratakan nilai smp tiap slice.

5. Membuat grafik nilai arus jenuh interval. 
6. Merata-ratakan nilai arus jenuh pada interval. Slice 6 detik awal dan 6 detik akhir tidak diikutkan karena merupakan indikator kehilangan awaI dan kehilangan akhir.

7. Mengkonversikan arus jenuh smp/6 detik menjadi smp/jam.

8. Membuat grafik model dasar arus jenuh rata-rata

\subsection{Kinerja bundaran dengan MKJI 1997}

Tahapan analisis kinerja bundaran dengan metode MKJI 1997 adalah sebagai berikut.

1. Mengonversi data arus ke dalam smp/jam dengan mengalikan kend/jam dengan emp (LV:1,0; HV:1,3; MC:0,5).

2. Memasukkan parameter geometrik bagian jalinan (lebar pendekat, lebar masuk ratarata, lebar jalinan, dan panjang jalinan)

3. Menghitung kapasitas dasar $\left(\mathbf{C}_{0}\right)$

4. Menentukan faktor-faktor penyesuaian, yaitu faktor penyesuaian ukuran kota $\left(\mathrm{F}_{\mathrm{CS}}\right)$, faktor penyesuaian tipe lingkungan jalan $\left(\mathrm{F}_{\mathrm{RSU}}\right)$

5. Menghitung kapasitas (C)

6. Menghitung derajat kejenuhan (DS)

7. Menghitung tundaan - bagian jalinan bundaran (DT)

8. Menghitung peluang antrian - bagian jalinan bundaran $(\mathrm{QP} \%)$

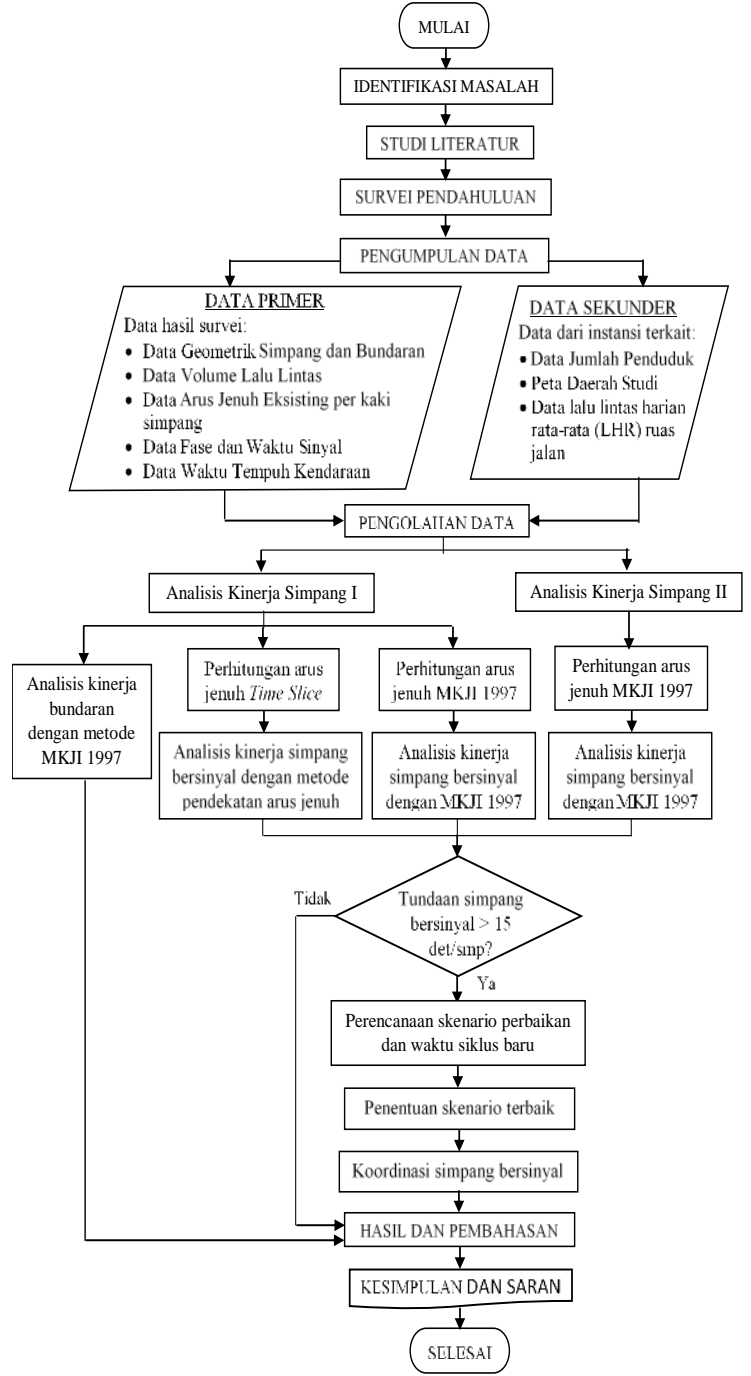

Gambar 1. Bagan alir kajian

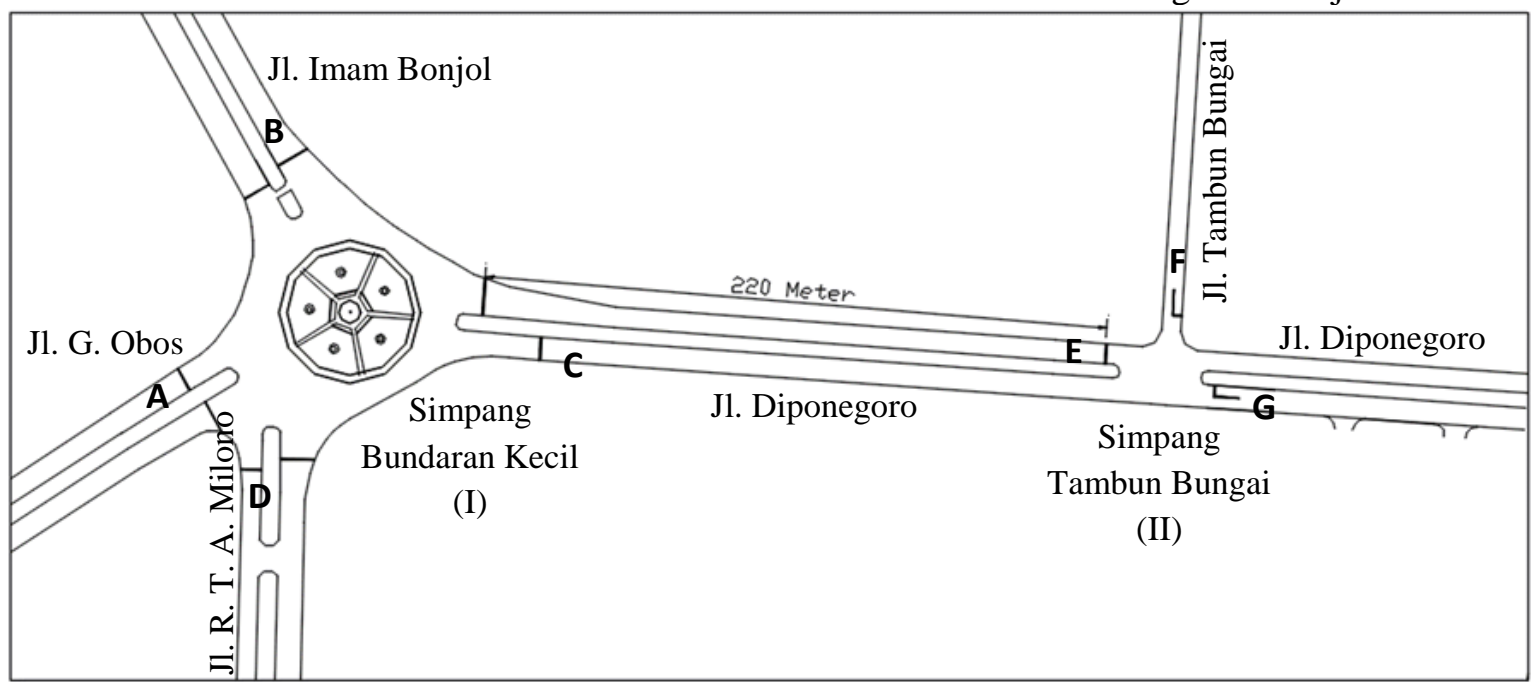

Gambar 2. Lokasi kajian 


\subsection{Kinerja simpang bersinyal dengan MKJI 1997}

Tahapan analisis kinerja simpang bersinyal dengan metode MKJI 1997 yaitu.

1. Mengonversi data arus ke dalam smp/jam dengan mengalikan kend/jam dengan emp:

3. Memasukkan parameter geometrik (lebar pendekat, lebar masuk, dan lebar keluar)

4. Menentukan lebar pendekat efektif (We)

5. Menghitung arus jenuh $(\mathrm{S})$

6. Menghitung kapasitas (C)

7. Menghitung derajat kejenuhan (DS)

8. Menghitung panjang antrian (QL)

9. Menghitung tundaan (D)

\subsection{Kinerja simpang bersinyal dengan metode pendekatan arus jenuh}

Analisis kinerja simpang bersinyal dengan metode pendekatan arus jenuh, tahapannya hampir sama dengan metode MKJI 1997. Yang membedakan yaitu digunakan nilai arus jenuh eksisting dari hasil survei arus jenuh time slice dan waktu hijau efektif yang diperoleh dari waktu hijau tampilan dikurang/ditambah dengan waktu hilang/tambahan.

\subsection{Perencanaan skenario perbaikan dan waktu siklus baru}

Perencanaan berdasarkan waktu siklus salah satu simpang. Kemudian simpang lain mengikuti agar didapat waktu siklus yang sama. Terdapat 10 skenario perencanaan, yaitu:

1. Waktu siklus sama dengan waktu siklus simpang I.

2. Waktu siklus sama dengan waktu siklus simpang II.

3. Waktu siklus sama dengan waktu siklus rata-rata dari kedua simpang.

4. Waktu siklus sama dengan waktu siklus baru sebesar 115 detik.

5. Waktu siklus sama dengan waktu siklus baru sebesar 120 detik.

6. Waktu siklus sama dengan waktu siklus simpang I serta ada perubahan geometrik.

7. Waktu siklus sama dengan waktu siklus simpang II serta ada perubahan geometrik.

8. Waktu siklus sama dengan waktu siklus rata-rata dari kedua simpang serta ada perubahan geometrik.

9. Waktu siklus sama dengan waktu siklus baru sebesar 115 detik serta ada perubahan geometrik.
- terlindung, LV:1,0; HV:1,3; MC:0,2

- terlawan, LV:1,0; HV:1,3; MC:0,4

2. Memasukkan parameter sinyal (fase sinyal, waktu antar hijau, waktu siklus, dan waktu hijau)

10.Waktu siklus sama dengan waktu siklus baru sebesar 120 detik serta ada perubahan geometrik.

\subsection{Penentuan skenario terbaik}

Skenario terbaik dipilih menggunakan metode pembobotan pada tiga jenis kinerja simpang, yaitu derajat kejenuhan (DS), panjang antrian (QL), dan tundaan (D). Kinerja terbaik akan mendapat prioritas utama yang ditandai oleh nominal angka besar. Perencanaan terpilih merupakan perencanaan yang memiliki nilai hasil pemilihan yang terbesar.

\subsection{Koordinasi simpang bersinyal}

Tahapan koordinasi sinyal antar simpang adalah:

1. Menyiapkan diagram ruang dan waktu untuk koordinasi. Sumbu x untuk waktu dan sumbu y untuk jarak antar simpang.

2. Membentuk lintasan aliran kendaraan dengan kemiringan berdasar waktu tempuh kendaraan.

3. Meletakkan waktu sinyal semua simpang pada diagram.

4. Menyesuaikan waktu hijau sesuai lintasan aliran kendaraan yang telah dibuat dengan cara menggeser secara horizontal sampai waktu hijau berada pada lintasan yang tepat

\section{HASIL DAN PEMBAHASAN}

Dari hasil pengumpulan data diperoleh data-data sebagai berikut:

\subsection{Data volume lalu lintas}

Survei dilakukan pada hari senin, tanggal 5 Oktober 2016 selama 9 jam yaitu pukul 06.00-09.00 WIB dan pukul 12.00-18.00 WIB. Ditempatkan tiga buah kamera sebagai alat perekam video yang dapat merekam pola pergerakan lalu lintas. Pada Tabel 1. diperlihatkan besarnya volume lalu lintas pada beberapa kondisi di masing-masing simpang. 
Tabel 1. Data volume lalu lintas

\begin{tabular}{cc}
\hline Kondisi lalu lintas & $\begin{array}{c}\text { Volume lalu lintas } \\
\text { (smp/jam) }\end{array}$ \\
\hline Simpang Bundaran Kecil & 3189,8 \\
- Puncak & 2738,6 \\
- Rata-rata & 2176,1 \\
- Rendah & \\
Simpang Tambun Bungai & 2259,9 \\
- Puncak & 1871,1 \\
- Rata-rata & 1362,1 \\
- Rendah & \\
\hline
\end{tabular}

\subsection{Data geometrik}

Dari hasil survei didapatkan data-data geometrik seperti pada Tabel 2 dan Tabel 3.

\subsection{Data waktu sinyal}

Dari data sinyal kondisi eksisting didapat jumlah fase dan waktu siklus. Simpang Bundaran Kecil memiliki empat fase dengan waktu siklus selama 112 detik. Dan simpang Tambun Bungai memiliki tiga fase dengan waktu siklus selama 67 detik. Pembagian lama waktu sinyal kedua simpang ditunjukkan pada Tabel 4.

Tabel 2. Data geometrik simpang

\begin{tabular}{lccc}
\hline Simpang & Pendekat & $\begin{array}{c}\text { Lebar } \\
\text { masuk }(\mathrm{m})\end{array}$ & $\begin{array}{c}\text { Lebar } \\
\text { keluar }(\mathrm{m})\end{array}$ \\
\hline Bundaran & $\mathrm{A}$ & 8,5 & 13,2 \\
Kecil & $\mathrm{B}$ & 12 & 12 \\
& $\mathrm{C}$ & 8 & 12,7 \\
Tambun & $\mathrm{D}$ & 7,5 & 10 \\
Bungai & $\mathrm{E}$ & 7 & 7 \\
& $\mathrm{~F}$ & 3,5 & 8 \\
& G-RT & 4 & 3,5 \\
\hline
\end{tabular}

Tabel 3. Data geometrik bundaran

\begin{tabular}{lcccc}
\hline & \multicolumn{4}{c}{ Jalinan } \\
\cline { 2 - 5 } & $\mathrm{AB}$ & $\mathrm{BC}$ & $\mathrm{CD}$ & $\mathrm{DA}$ \\
\hline $\begin{array}{l}\text { Lebar } \\
\text { masuk 1 }\end{array}$ & 8,5 & 12 & 8 & 7,5 \\
$\begin{array}{l}\text { Lebar } \\
\text { masuk 2 }\end{array}$ & 20,3 & 13 & 12,7 & 23,8 \\
$\begin{array}{l}\text { Lebar rata- } \\
\text { rata (e) }\end{array}$ & 14,4 & 12,5 & 10,35 & 15,65 \\
$\begin{array}{l}\text { Lebar } \\
\text { jalinan (w) }\end{array}$ & 13 & 9 & 8 & 36,3 \\
$\begin{array}{l}\text { Panjang } \\
\text { jalinan (L) }\end{array}$ & 57,2 & 66,8 & 73,8 & 20,1 \\
\hline
\end{tabular}

Tabel 4. Data waktu sinyal simpang

\begin{tabular}{ccccc}
\hline \multirow{2}{*}{ Simpang } & \multirow{2}{*}{ Pendekat } & \multicolumn{3}{c}{ Waktu Sinyal } \\
\cline { 3 - 5 } & & Hijau & Merah & Kuning \\
\hline \multirow{3}{*}{ Bundaran } & A & 21 & 88 & 3 \\
Kecil & B & 21 & 88 & 3 \\
& C & 21 & 88 & 3 \\
Tambun & D & 21 & 88 & 3 \\
Bungai & E & 17 & 47 & 3 \\
& F & 14 & 50 & 3 \\
& G-RT & 15 & 49 & 3 \\
\hline
\end{tabular}

\subsection{Kinerja bundaran dengan MKJI 1997}

Kinerja bundaran mengacu pada MKJI 1997. Diperoleh hasil bahwa jalinan DA memiliki kinerja paling rendah, yaitu nilai DS 0,901. Jalinan AB, BC, dan CD masih memiliki kinerja yang baik, yaitu DS di bawah 0,75 yang selengkapnya dapat dilihat pada Tabel $\mathbf{5}$.

Tabel 5. Kinerja bundaran pada simpang bundaran kecil dengan MKJI 1997

\begin{tabular}{|c|c|c|c|c|c|c|}
\hline $\begin{array}{l}\text { Lalu } \\
\text { Lintas }\end{array}$ & $\begin{array}{l}\text { Bagian } \\
\text { Jalinan }\end{array}$ & $\begin{array}{c}\mathrm{C} \\
(\mathrm{smp} / \mathrm{jam})\end{array}$ & $\begin{array}{c}\mathrm{Q} \\
\text { (smp/jam) }\end{array}$ & DS & $\begin{array}{c}\text { DT } \\
(\operatorname{det} / \mathrm{smp})\end{array}$ & $\begin{array}{l}\text { QP } \\
(\%)\end{array}$ \\
\hline \multirow{4}{*}{ Puncak } & $\mathrm{AB}$ & 5758 & 2949 & 0,512 & 2,40 & $6-14$ \\
\hline & $\mathrm{BC}$ & 4888 & 2516 & 0,515 & 2,41 & $6-14$ \\
\hline & $\mathrm{CD}$ & 4159 & 2250 & 0,541 & 2,54 & $7-15$ \\
\hline & DA & 2793 & 2516 & 0,901 & 8,23 & $27-58$ \\
\hline \multirow{4}{*}{ Rendah } & $\mathrm{AB}$ & 5783 & 1856 & 0,321 & 1,50 & $3-6$ \\
\hline & $\mathrm{BC}$ & 4930 & 1583 & 0,321 & 1,51 & $3-6$ \\
\hline & $\mathrm{CD}$ & 4176 & 1551 & 0,371 & 1,74 & $4-8$ \\
\hline & DA & 2816 & 1678 & 0,596 & 2,78 & $8-19$ \\
\hline \multirow{4}{*}{ Rata-rata } & $\mathrm{AB}$ & 5778 & 2304 & 0,399 & 1,87 & $4-9$ \\
\hline & $\mathrm{BC}$ & 4907 & 2140 & 0,436 & 2,05 & $5-10$ \\
\hline & $\mathrm{CD}$ & 4180 & 1998 & 0,478 & 2,24 & $5-12$ \\
\hline & DA & 2781 & 2052 & 0,738 & 4,37 & $14-33$ \\
\hline
\end{tabular}


Tabel 6. Kinerja simpang bersinyal bundaran kecil dengan MKJI 1997 (lanjutan)

\begin{tabular}{ccccccccc}
\hline $\begin{array}{c}\text { Lalu } \\
\text { Lintas }\end{array}$ & Pendekat & $\begin{array}{c}\mathrm{S} \\
(\mathrm{smp} / \mathrm{jam})\end{array}$ & $\begin{array}{c}\mathrm{Q} \\
(\mathrm{smp} / \mathrm{jam})\end{array}$ & $\begin{array}{c}\mathrm{C} \\
(\mathrm{smp} / \mathrm{jam})\end{array}$ & $\mathrm{DS}$ & QL (m) & $\begin{array}{c}\text { D } \\
\text { (det/smp) }\end{array}$ & $\begin{array}{c}\text { Dsimpang } \\
\text { (det/smp) }\end{array}$ \\
\hline \multirow{5}{*}{ Puncak } & A & 3880 & 619 & 727 & 0,851 & 72 & 59,09 & \\
& $\mathrm{~B}$ & 5404 & 857 & 1013 & 0,846 & 67 & 55,62 & 324,66 \\
& $\mathrm{C}$ & 3660 & 896 & 686 & 1,305 & 464 & 614,96 & \\
& $\mathrm{D}$ & 3545 & 818 & 665 & 1,231 & 386 & 489,58 & \\
Rendah & $\mathrm{A}$ & 3819 & 304 & 716 & 0,424 & 32 & 43,74 & \\
& $\mathrm{~B}$ & 5411 & 658 & 1015 & 0,649 & 47 & 47,37 & 59,88 \\
& $\mathrm{C}$ & 3629 & 592 & 680 & 0,870 & 75 & 62,41 & \\
Rata- & $\mathrm{D}$ & 3543 & 622 & 664 & 0,936 & 94 & 78,59 & \\
rata & $\mathrm{A}$ & 3862 & 479 & 724 & 0,662 & 51 & 48,24 & \\
& $\mathrm{~B}$ & 5401 & 802 & 1013 & 0,792 & 60 & 52,20 & 152,40 \\
\hline
\end{tabular}

Tabel 7. Kinerja simpang bersinyal Tambun Bungai dengan MKJI 1997

\begin{tabular}{|c|c|c|c|c|c|c|c|c|}
\hline $\begin{array}{c}\text { Lalu } \\
\text { Lintas }\end{array}$ & Pendekat & $\begin{array}{c}\mathrm{S} \\
(\mathrm{smp} / \mathrm{jam})\end{array}$ & $\begin{array}{c}\mathrm{Q} \\
(\mathrm{smp} / \mathrm{jam})\end{array}$ & $\begin{array}{c}\mathrm{C} \\
(\mathrm{smp} / \mathrm{jam})\end{array}$ & DS & $\mathrm{QL}(\mathrm{m})$ & $\begin{array}{c}\mathrm{D} \\
\text { (det/smp) }\end{array}$ & $\begin{array}{l}\text { Dsimpang } \\
\text { (det/smp) }\end{array}$ \\
\hline \multirow{3}{*}{ Puncak } & $\mathrm{E}$ & 3146 & 999 & 798 & 1,252 & 479 & 508,37 & \multirow{3}{*}{345,46} \\
\hline & $\mathrm{F}$ & 1827 & 237 & 382 & 0,619 & 48 & 31,26 & \\
\hline & G-RT & 1892 & 282 & 424 & 0,666 & 49 & 31,67 & \\
\hline \multirow{3}{*}{ Rendah } & $\mathrm{E}$ & 3141 & 602 & 797 & 0,755 & 51 & 31,56 & \multirow{3}{*}{29,88} \\
\hline & F & 1864 & 162 & 390 & 0,415 & 35 & 27,39 & \\
\hline & G-RT & 1892 & 120 & 424 & 0,283 & 26 & 24,83 & \\
\hline \multirow{3}{*}{$\begin{array}{l}\text { Rata- } \\
\text { rata }\end{array}$} & $\mathrm{E}$ & 3155 & 822 & 801 & 1,027 & 146 & 125,49 & \multirow{3}{*}{91,66} \\
\hline & $\mathrm{F}$ & 1855 & 239 & 388 & 0,616 & 48 & 31,11 & \\
\hline & G-RT & 1892 & 204 & 424 & 0,481 & 35 & 26,07 & \\
\hline
\end{tabular}

\subsection{Kinerja simpang bersinyal dengan MKJI 1997}

Kinerja simpang bersinyal mengacu pada MKJI 1997, kedua simpang memiliki tipe pendekat terlindung. Diperoleh bahwa pada kondisi lalu lintas rata-rata dan puncak, pada pendekat $\mathrm{C}$ dan $\mathrm{D}$ simpang Bundaran Kecil dan pendekat E simpang Tambun Bungai memiliki nilai tundaan $>60 \mathrm{det} / \mathrm{smp}$, yang berarti tingkat pelayanan $\mathrm{F}$.

Adapun kinerja kedua simpang dapat dilihat pada Tabel 6 dan Tabel 7. Kriteria tingkat pelayanan untuk simpang bersinyal seperti pada Tabel 8.

Tabel 8. Tingkat pelayanan simpang bersinyal

\begin{tabular}{cc}
\hline Tingkat Pelayanan & Nilai tundaan (det/smp) \\
\hline A & $\leq 5,0$ \\
B & $5,1-15,0$ \\
C & $15,1-25,0$ \\
D & $25,1-40,0$ \\
E & $40,0-60,0$ \\
F & $>60,0$ \\
\hline
\end{tabular}

Sumber: PM No. 96 Tahun 2015

\subsection{Analisis arus jenuh interval}

Analisis arus jenuh dilakukan terhadap masing-masing kaki simpang pada simpang Bundaran Kecil. Hasil analisis nilai arus jenuh interval rata-rata $\left(S_{\text {rata-rata }}\right)$ dan waktu hijau efektif (g) seluruh kaki simpang terangkum pada Tabel 10. Berikut ditampilkan analisis pada kaki simpang B.

Tabel 9. Arus jenuh pada kaki simpang B

\begin{tabular}{cccc}
\hline \multicolumn{2}{c}{ Interval waktu } & \multicolumn{2}{c}{$\begin{array}{c}\text { Arus jenuh interval } \\
(\text { S interval) }\end{array}$} \\
\hline 0,0 & 6,0 & 3,091 & smp/6 detik \\
6,1 & 12,0 & 8,200 & smp/6 detik \\
12,1 & 18,0 & 8,345 & smp/6 detik \\
18,1 & 24,0 & 6,018 & smp/6 detik \\
\hline
\end{tabular}




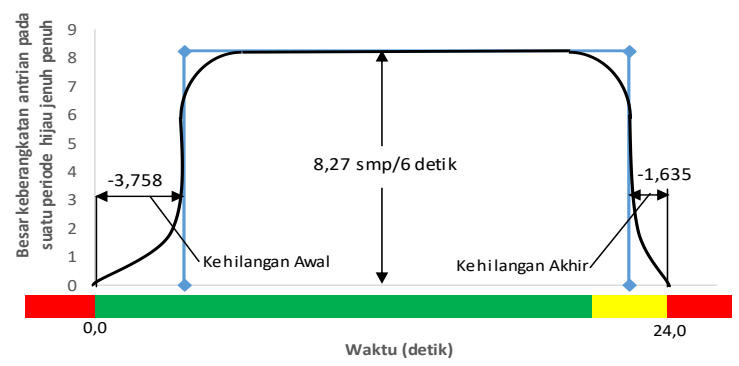

Gambar 3. Grafik model arus jenuh dasar kaki simpang B

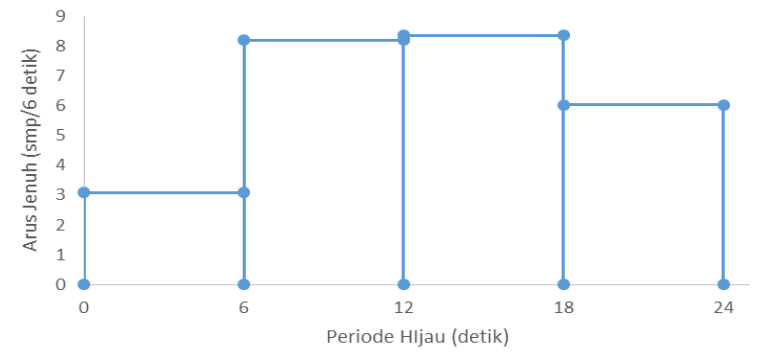

Gambar 4. Grafik arus jenuh interval kaki simpang B

Tabel 10. Hasil analisis arus jenuh interval rata-rata dan waktu hijau efektif

\begin{tabular}{cccccc}
\hline Kaki & Lokasi kaki & Arus jenuh interval rata- \\
simpang & rata (smp/jam) & $\begin{array}{c}\text { Waktu hijau } \\
\text { tampilan } \\
\text { (detik) }\end{array}$ & $\begin{array}{c}\text { Waktu } \\
\text { hilang/ } \\
\text { tambahan } \\
\text { (detik) }\end{array}$ & $\begin{array}{c}\text { Waktu hijau } \\
\text { efektif } \\
\text { (detik) }\end{array}$ \\
\hline A & Jl. G. Obos & 3859 & 21 & 0,248 & 21,248 \\
B & Jl.Imam Bonjol & 4964 & 21 & $-2,393$ & 18,607 \\
C & Jl. Diponegoro & 3846 & 21 & 1,259 & 22,259 \\
D & Jl.RTA Milono & 3743 & 21 & $-0,307$ & 20,693 \\
\hline
\end{tabular}

Tabel 11. Kinerja simpang bersinyal bundaran kecil dengan metode pendekatan arus jenuh

\begin{tabular}{|c|c|c|c|c|c|c|c|c|}
\hline $\begin{array}{l}\text { Lalu } \\
\text { Lintas }\end{array}$ & Pendekat & $\begin{array}{c}\mathrm{S} \\
(\mathrm{smp} / \mathrm{jam})\end{array}$ & $\begin{array}{c}\mathrm{Q} \\
(\mathrm{smp} / \mathrm{jam})\end{array}$ & $\begin{array}{c}\mathrm{C} \\
(\mathrm{smp} / \mathrm{jam})\end{array}$ & DS & $\mathrm{QL}(\mathrm{m})$ & $\begin{array}{c}\mathrm{D} \\
\text { (det/smp) }\end{array}$ & $\begin{array}{l}\text { Dsimpang } \\
\text { (det/smp) }\end{array}$ \\
\hline \multirow{4}{*}{ Puncak } & $\mathrm{A}$ & 3859 & 619 & 732 & 0,845 & 71 & 58,30 & \multirow{4}{*}{264,26} \\
\hline & B & 4964 & 857 & 825 & 1,039 & 120 & 161,71 & \\
\hline & $\mathrm{C}$ & 3846 & 896 & 764 & 1,172 & 335 & 377,25 & \\
\hline & $\mathrm{D}$ & 3743 & 818 & 692 & 1,183 & 339 & 403,78 & \\
\hline \multirow{4}{*}{ Rendah } & A & 3859 & 304 & 732 & 0,415 & 32 & 43,48 & \multirow{4}{*}{56,24} \\
\hline & B & 4964 & 658 & 825 & 0,798 & 51 & 55,14 & \\
\hline & $\mathrm{C}$ & 3846 & 592 & 764 & 0,775 & 69 & 52,23 & \\
\hline & $\mathrm{D}$ & 3743 & 622 & 692 & 0,899 & 87 & 67,43 & \\
\hline \multirow{4}{*}{$\begin{array}{l}\text { Rata- } \\
\text { rata }\end{array}$} & A & 3859 & 479 & 732 & 0,654 & 51 & 47,83 & \multirow{4}{*}{98,15} \\
\hline & B & 4964 & 802 & 825 & 0,972 & 80 & 91,78 & \\
\hline & $\mathrm{C}$ & 3846 & 773 & 764 & 1,012 & 142 & 126,28 & \\
\hline & $\mathrm{D}$ & 3743 & 684 & 692 & 0,989 & 123 & 109,07 & \\
\hline
\end{tabular}

4.7. Kinerja simpang bersinyal dengan metode pendekatan arus jenuh

Kinerja simpang bersinyal dengan metode pendekatan arus jenuh menggunakan nilai arus jenuh eksisting dan waktu hijau efektif dari hasil analisis arus jenuh interval. Hasil analisis metode pendekatan arus jenuh mendekati dan dapat mewakili kondisi di lapangan, sehingga akan digunakan pada perhitungan selanjutnya. Adapun kinerjanya dapat dilihat pada Tabel 11.

\subsection{Perencanaan skenario perbaikan dan waktu siklus baru}

Terdapat 10 skenario perencanaan dalam kajian ini. Skenario yang direncanakan berupa pengaturan ulang sinyal, perubahan geometrik dan kombinasinya. Penghitungan kinerjanya berdasarkan kondisi lalu lintas rata-rata dengan metode pendekatan arus jenuh. Adapun perubahan geometrik yang direncanakan seperti pada Tabel 12.

Tabel 12. Perubahan geometrik yang direncanakan

\begin{tabular}{cccc}
\hline Simpang & Pendekat & $\begin{array}{c}\text { Skenario 1 } \\
\text { s/d 5 }\end{array}$ & $\begin{array}{c}\text { Skenario 6 } \\
\text { s/d 10 }\end{array}$ \\
\hline \multirow{4}{*}{ I } & A & 8,5 & 10,5 \\
& B & 12 & 13 \\
& C & 8 & 11 \\
& D & 7,5 & 10,5 \\
II & E & 7 & 9 \\
& F & 3,5 & 4 \\
& G-RT & 4 & 4 \\
\hline
\end{tabular}




\subsection{Penentuan kinerja terbaik}

Kinerja terbaik ditentukan dengan penilaian berdasarkan nilai kinerja rata-rata kedua simpang setiap skenario pada tiga jenis kinerja, yaitu derajat kejenuhan (DS), panjang antrian (QL), dan tundaan (D). Pada Tabel 13 dapat dilihat perbandingan nilai dari masingmasing skenario. Hasil penilaian merupakan jumlah ketiga jenis kinerja, dua skenario terbaik yaitu skenario 7 dan 8 .

Tabel 13. Pemilihan skenario kinerja terbaik

\begin{tabular}{lccccccccc}
\hline $\begin{array}{l}\text { Kondisi } \\
\text { rata-rata }\end{array}$ & $\begin{array}{c}\text { CT } \\
\text { detik) }\end{array}$ & DS & QL & D & \multicolumn{2}{c}{ Tingkat Pemilihan (TP) } & $\begin{array}{c}\text { Total } \\
\text { Pemilihan }\end{array}$ & $\begin{array}{c}\text { Urutan } \\
\text { Pemilihan }\end{array}$ \\
\hline Eksisting & & 0,822 & 89 & 79,66 & DS & QL & D & & 7 \\
Skenario 1 & 112 & 0,718 & 71 & 48,02 & 3 & 3 & 4 & 10 & 9 \\
Skenario 2 & 67 & 0,839 & 59 & 52,54 & 1 & 5 & 1 & 7 & 6 \\
Skenario 3 & 90 & 0,760 & 62 & 44,28 & 2 & 4 & 7 & 13 & 8 \\
Skenario 4 & 115 & 0,717 & 72 & 48,90 & 3 & 2 & 3 & 8 & 9 \\
Skenario 5 & 120 & 0,709 & 74 & 50,01 & 4 & 1 & 2 & 7 & 4 \\
Skenario 6 & 112 & 0,583 & 54 & 42,47 & 7 & 8 & 6 & 21 & 1 \\
Skenario 7 & 67 & 0,676 & 38 & 31,32 & 5 & 10 & 10 & 25 & 2 \\
Skenario 8 & 90 & 0,612 & 46 & 36,41 & 6 & 9 & 9 & 24 & 3 \\
Skenario 9 & 115 & 0,580 & 55 & 43,29 & 7 & 7 & 8 & 22 & 3 \\
Skenario10 & 120 & 0,574 & 57 & 44,64 & 8 & 6 & 5 & 19 & 5 \\
\hline
\end{tabular}

\subsection{Koordinasi simpang bersinyal}

Kaki simpang yang akan dikoordinasikan yaitu kaki simpang A (simpang I) dan kaki simpang E (simpang II). Jarak kedua kaki simpang yaitu 355 meter. Berdasarkan hasil survei waktu tempuh didapat kecepatan $85 \%$ sebesar $32,2 \mathrm{~km} / \mathrm{jam}$, sehingga waktu tempuh sebesar 40 detik. Menurut MKJI (1997), bahwa waktu hijau yang lebih pendek dari 10 detik harus dihindari. Dengan pertimbangan tersebut, maka dipilih skenario 8 dengan waktu hijau sebesar 13 detik. Diagram koordinasi dari skenario 8 ditunjukkan pada Gambar 5.

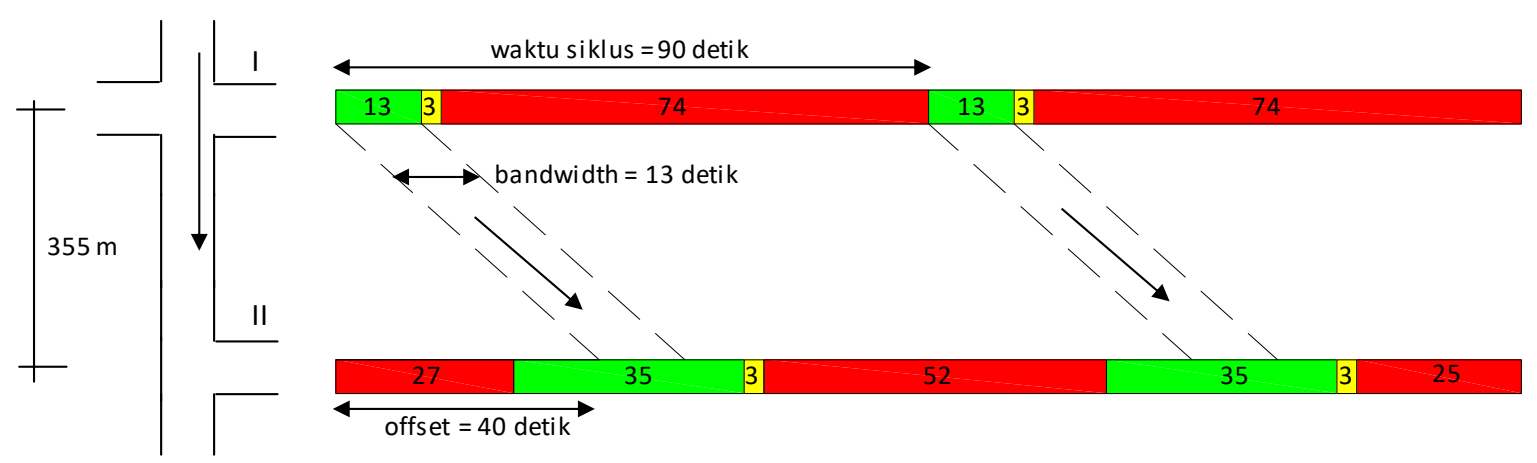

Gambar 5. Diagram koordinasi sinyal kedua simpang

\section{KESIMPULAN DAN SARAN}

\subsection{Kesimpulan}

Dari hasil analisa dan pembahasan serta untuk menjawab permasalahan di awal, dapat disimpulkan sebagai berikut.

1. Berdasarkan dua metode yang digunakan pada simpang bersinyal Bundaran Kecil, yaitu metode MKJI 1997 dan metode pendekatan arus jenuh. Kedua metode tersebut sama-sama menghasilkan kinerja dengan tingkat pelayanan bernilai $\mathrm{F}$ untuk kondisi lalu lintas puncak dan rata-rata.
Nilai tundaan rata-rata simpang pada kondisi lalu lintas puncak dengan metode MKJI 1997 sebesar 324,66 det/smp dan metode pendekatan arus jenuh sebesar 264,26 det/smp.

2. Simpang Bundaran Kecil memiliki permasalahan yaitu pada kinerja bundaran, terjadi derajat kejenuhan (DS) sebesar 0,901 pada jalinan DA (Jl. R.T.A. Milono - Jl. G. Obos) untuk kondisi lalu lintas puncak. Sedangkan jalinan AB (Jl. G. Obos - Jl. Imam Bonjol), jalinan BC (Jl. Imam Bonjol 
- Jl. Diponegoro), dan jalinan CD (Jl. Diponegoro - Jl. R.T.A. Milono) masih memiliki kinerja yang baik, yaitu nilai DS masih di bawah 0,75 .

3. Dalam perancangan koordinasi sinyal dipilih skenario terbaik yaitu skenario 8 dengan waktu siklus sebesar 90 detik serta direncanakan perubahan geometrik pada simpang Bundaran Kecil dan simpang Tambun Bungai. Koordinasi sinyal dilakukan dengan menggunakan waktu offset sebesar 40 detik. Dari diagram koordinasi pada Gambar 5 didapatkan bandwidth sebesar 13 detik. Setelah dilakukan koordinasi sinyal, kinerja simpang Bundaran Kecil dan simpang Tambun Bungai mengalami peningkatan yaitu tingkat pelayanan yang semula bernilai F menjadi D pada kondisi lalu lintas rata-rata.

\subsection{Saran}

Adapun saran - saran yang disampaikan dalam kajian ini antara lain:

1. Perlu dilakukan kajian lebih lanjut dengan menggunakan software serta metode pendekatan lain yang sesuai dengan kondisi di Indonesia untuk mendukung keakuratan hasil kajian yang sudah ada.

2. Perlu dilakukan kajian lebih lanjut untuk perancangan koordinasi sinyal dengan kondisi tanpa bundaran.
3. Perlu adanya rekayasa lalu lintas secara berkala karena lalu lintas yang terus mengalami peningkatan setiap tahunnya.

\section{DAFTAR PUSTAKA}

[1] Badan Pusat Statistik Kota Palangka Raya. (2016). Palangka Raya Dalam Angka 2016. Palangka Raya: BPS

[2] Direktorat Jenderal Bina Marga. (1997). Manual Kapasitas Jalan Indonesia 1997. Jakarta: Departemen Pekerjaan Umum

[3] Direktorat Jenderal Perhubungan Darat. (2015). Peraturan Menteri Perhubungan Nomor PM 96 Tahun 2015 tentang Pedoman Pelaksanaan Kegiatan Manajemen dan Rekayasa Lalu Lintas. Jakarta: Kementerian Perhubungan

[4] Khisty C. J. \& Lall B. K. (2006). Dasar-Dasar Rekayasa Transportasi. Jakarta: Penerbit Erlangga

[5] Munawar, A. (2009). Manajemen Lalu Lintas Perkotaan. Jogjakarta: Penerbit Beta Offset

[6] Road Research Laboratory. (1963). Road Note 34, A Method of Measuring Saturation Flow at Traffic Signals. London: H.M. Stationery Office

[7] Shane, Mc. W. R. \& Roess, R. P. (1990). Traffic Engineering. New Jersey: Prentice Hall Inc

[8] Yuliantana, S. A. \& Patandianan, Y. K. (2013). Kajian Arus Jenuh Pada Simpang Bersinyal di Kota Malang Bagian Selatan. Malang: Universitas Brawijaya 